\title{
Editorial
}

Digestion

\section{Informed Consent: Still Far from Ideal?}

\author{
Spiros D. Ladas \\ Hepato-Gastroenterology Unit, 2nd Department of Medicine, Medical School, Athens University, \\ 'Attikon' University General Hospital, Haidari, Greece
}

In modern health care, paternalism has given place to shared information, shared decision making and shared responsibilities between doctors and patients [1]. To achieve these goals, doctors must give full and unbiased information to patients, provide adequate time for discussion, and encourage them to participate in the process of decision making. Informed consent is not a momentary action of getting patient's signature on a form. It is a dynamic process of events which rests upon mutual respect and honors the doctor-patient relationship.

Informed consent derives from the principle of respecting the patient's autonomy, i.e., the patient has the right to decide about proposed treatment or procedure. The process of informed consent requires that the doctor explains to the patient the benefits and risks of any suggested test or treatment and obtains the patient's deliberate agreement to proceed $[2,3]$.

Focusing this article on diagnostic endoscopy, informing a patient and obtaining written informed consent is not that simple because endoscopies are invasive procedures. What would a 'reasonable patient' wish to know so that he/she will be appropriately informed and make a deliberate decision [4]? The elements of adequate disclosure should include: (1) the reason that gastroscopy is indicated; (2) the nature (description) of gastroscopy, i.e., what will happen before, during and after the procedure; (3) diagnostic benefits, including therapeutic options; (4) possible risks, complications and mortality rates; (5) alternative diagnostic tests and their advantages and disadvantages, as compared to gastroscopy, and (6) a clear explanation that the patient may withdraw consent at any time prior to endoscopy.

\section{KARGER}

Fax +41613061234 E-Mail karger@karger.ch www.karger.com (c) 2006 S. Karger AG, Basel

0012-2823/06/0733-0187\$23.50/0

Accessible online at:

www.karger.com/dig
This information should be given to patients in clear understandable language, adapted to the patients' needs and intelligence [5]. The competence of patients to understand this information should be assessed by the endoscopist. A crucial unresolved issue is the amount of information that the endoscopist should provide the patient about the complication and mortality rates of diagnostic gastroscopy. A published survey concluded that most patients wish to be informed of a risk greater than $1: 1,000$ [6]. On the contrary, another survey showed that $19 \%$ of gastroscopy patients wanted to know all possible complications [7], and a third survey reported that $16 \%$ of clinical negligence specialists suggested that patients should be told of risks of 1:1,000,000 [4].

Additional important issues in the process of informed consent include: (1) who should be the responsible person to provide the information and obtain the consent form - endoscopist, referring physician, nurse assistant or another doctor of the staff $[8,9]$, and (2) what is the best way to inform patients - verbally, leaflet, videotape, postal or e-mail letter [10]. Written information is undoubtedly useful and advisable, but cannot replace the need for doctor-patient verbal communication and discussion. Not least the timing of information is mandatory. Was information given at a counseling session with the patient a month before the examination or just before the patient was sedated for the procedure? Furthermore, nowadays several patients would wish to know the name of doctor who will be in charge or will perform the examination - consultant, trainee (supervised?) or a trained nurse. They would also like to know the years of experience and technical skills of the endoscopist $[6,11]$, including personal success and complication rates [12].
Prof. Spiros D. Ladas, MD

Hepato-Gastroenterology Unit, 2nd Department of Medicine

Medical School, Athens University, 'Attikon' University General Hospital

1 Rimini Street, GR-12464 Haidari (Greece)

E-Mailsdladas@hol.gr 
In this issue of Digestion Woodrow and Jenkins [13] investigated the completeness of the consent process in outpatients undergoing gastroscopy. They have shown that about $10 \%$ of the patients did not understand why they were having a gastroscopy and about $50 \%$ were not told the risks of the procedure and were not given the opportunity to decline. Even more important $40 \%$ did not read the consent form before signing it [13]. Two studies from the UK also showed that only $25-50 \%$ of the patients had carefully read the consent form before signing it $[14,15]$ and $51 \%$ were dissatisfied because they wished to have more information about risks $(42 \%)$ and alternative tests (49\%) to gastroscopy [15]. Despite published recommendations and guidelines in several countries by endoscopy societies $[8,9,16]$, there is growing evidence that there are many deficiencies in the process of obtaining a valid informed consent. A survey assessing the current practice of doctors obtaining informed consent for outpatient endoscopy in the north-west of England showed a wide variation in practice among doctors regarding information given to patients about procedure risks and the person who will perform the endoscopic procedure [17]. Variation in practice was recently confirmed in a survey among presidents or secretaries of European endoscopy societies, where $23 \%$ of the endoscopists did not provide sufficient time for discussion with their patients and only $23 \%$ reported related mortality rates [18]. Even worse, another unpublished survey by the European Society of Gastrointestinal Endoscopy among its member societies, with a high response rate, showed that patients do not sign a consent form before gastroscopy in more than half of the responders' endoscopy units.

All the above indicate that there are numerous deficiencies in the process of informed consent for gastrointestinal endoscopic procedures in many European countries. These violate patients' self-determination, have a negative influence on the doctor-patient relationship and could lead to malpractice claims by patients $[12,19,20]$. The workload of endoscopic procedures has very much increased over the past 30 years, but the lack of doctor's time is not an excuse for violating patient's rights and doctor's ethical obligations.

\section{References}

1 Coulter A: paternalism or partnership? BMJ 1999;319:719-720.

2 Kirsch M: The myth of informed consent. Am J Gastroenterol 2000;95:588-589.

3 Feld AD: Informed consent: not just for procedures anymore. Am J Gastroenterol 2004; 99:977-980.

4 Mayberry MK, Mayberry JF: Towards better informed consent in endoscopy: a study of information and consent processes in gastroscopy and flexible sigmoidoscopy. Eur J Gastroenterol Hepatol 2001;13:1467-1476.

5 Lavelle-Jones C, Byrne DJ, Rice P, Cuschieri A: Factors affecting quality of informed consent. BMJ 1993;306:885-890.

6 Newton-Howes PA, Bedford ND, Dobbs BR, Frizelle FA: Informed consent: what do patients want to know? NZ Med J 1998;111: 340-342.

7 Brooks AJ, Hurlstone DP, Fotheringham J, Gane J, Sanders DS, McAlindon ME: Information required to provide informed consent for endoscopy: an observational study of patients' expectations. Endoscopy 2005;37: $1136-1139$
8 Stanciu C, Novis B, Ladas S, Sommerville A, Zabovowski P, Isaacs P, Papatheodoridis G, James T: Recommendations of the ESGE workshop on Informed Consent for Digestive Endoscopy. First European Symposium on Ethics in Gastroenterology and Digestive Endoscopy, Kos, Greece, June 2003. Endoscopy 2003;35:772-774.

9 British Society of Gastroenterology: Guidelines for Informed Consent for Endoscopic Procedures. Guidelines in Gastroenterology, London, British Society of Gastroenterology, 1999, http/www.bsg.org.uk

10 Plumeri PA: Informed consent and the gastrointestinal endoscopist. Gastrointest Endosc 1985;31:218-221.

11 Yacavone RF, Locke GR 3rd, Gostout CJ, Rockwood TH, Thieling S, Zinsmeister AR: Factors influencing patient satisfaction with GI endoscopy. Gastrointest Endosc 2001;53: 703-710.

12 Cotton PB: Analysis of 59 ERCP lawsuits; mainly about indications. Gastrointest Endosc 2006;63:378-382.

13 Woodrow SR, Jenkins AP: How thorough is the process of informed consent prior to outpatient gastroscopy? A study of practice in a United Kingdom district hospital. Digestion 2006;73:189-197.
14 Pereira SP, Hussaini SH, Wilkinson ML: Informed consent for upper gastrointestinal endoscopy. Gut 1995;37:151-153.

15 Basi E, Brown E, Kapoor N, Bodger K: Dissatisfaction with consent for diagnostic gastrointestinal endoscopy. Dig Dis 2002;20: 275-279.

16 American Society for Gastrointestinal Endoscopy: Informed consent for gastrointestinal endoscopy. Gastrointest Endosc 1988; 34(suppl 3):26s-27s.

17 Thuraisingam AI: Survey of informed consent for endoscopy. Gut 2001;49:874.

18 Triantafyllou K, Stanciu C, Kruse A, Malfertheiner P, Axon A, Ladas SD, European Society of Gastrointestinal Endoscopy: Informed consent for gastrointestinal endoscopy: a 2002 ESGE survey. Dig Dis 2002;20:280283.

19 Neale G: Reducing risks in gastroenterological practice. Gut 1998;42:139-142.

20 Levine EG, Brandt LJ, Plumeri PA: Informed consent: a survey of physician outcomes and practices. Gastrointest Endosc 1995;41:448452 . 